\title{
Inclusive Growth in Science-The Importance of Investing in Employee Development and A Fairer Sharing of Opportunities and Benefits
}

\author{
Thirunavukkarasu $\mathrm{S}^{*}$ \\ Washington University in St Louis, USA
}

*Corresponding author: Shyamala Thirunavukkarasu, Washington University in St Louis, 660 S Euclid Ave, St Louis 63110 MO, USA.

To Cite This Article: Thirunavukkarasu S. Inclusive Growth in Science-The Importance of Investing in Employee Development and A Fairer Sharing of Opportunities and Benefits. Am J Biomed Sci \& Res. 2021 - 13(5). AJBSR.MS.ID.001918. DOI: 10.34297/AJBSR.2021.13.001918.

Received: 眥 July 20, 2021; Published: 眥 August 04, 2021

\section{Introduction}

As the COVID-19 pandemic cruises onwards, the scientific community has been left to grapple with the fact that many workplace practices previously considered to be the norm are now outdated. This new reality underpins the enormous importance of not just employee adaptability but also the necessity of employers to adapt to changing times to ensure employee job satisfaction. Job satisfaction is a critical component of any successful organization, and it is common knowledge that happy employees are productive employees who deliver stellar performance, enhancing the overall stature of an organization. Enhancing individual well-being and engaging in inclusive growth across the team could be a productive strategy for organizations irrespective of its size or stature. Inclusive growth is a concept that is prevalent in the economic field, which advocates equal opportunities for all stakeholders during economic growth, with shared benefits obtainable by every section of society [1]. This term can be adapted to the scientific community in terms of employee development and potential for employees to benefit from opportunities made available by organizational leadership.

Strategic investing in employee development has a two-pronged advantage. Firstly, it helps in attracting a talented workforce to the organization. In current times, employees seek more fulfillment rather than just to be perceived as a labor resource. When potential employees are aware that an organizational leadership is committed to invest in their development, they automatically translate that to a leadership that will value them and want to see them grow professionally and personally. This is an attractive incentive for potential employees to join the workforce apart from the monetary benefits that the position might offer.

Secondly, employee development and inclusive growth is an investment that pays off in the long run for the organization. While it is inevitable that investing in employee development costs money and the returns might not be instantaneously realized, it ultimately does have an impact eventually, the most significant of which is employee retention. Long-term employees tend to form greater connections with one another which builds up trust and a sense of loyalty among team members of an organization. A report published in 2018 states that $93 \%$ of employees would stay at a company longer if it invested in their careers [2]. Beyond simply promoting employee retention, investing in employee development creates a clear path for employees to have an upward career progression. And it would be prudent for the leadership to facilitate both within organization upward movement and outside the organization movement without creating roadblocks if an employee so chooses. As this helps build the image of the employer as someone who is invested in an individual's morale and development regardless of payback to the organization. In doing so it paves way for fresh talent to enter into the employer's workforce which creates fresh ideas and new perspectives all of which are crucial for transformative growth of the organization in its entirety.

Hence, it would be callow for an organization's leadership to assume that employee satisfaction, bonding and loyalty comes from providing periodic pep talks or organizing the episodic lunch / 
dinner gatherings or work outings. While these things can certainly help boost employee job satisfaction ostensibly, true satisfaction and togetherness comes from creating work environments where the individuals sense that they have a fair share in the opportunities provided, where all employees can contribute to reach their fullest professional potential and eventually reap a share in the organization's success. When employees know that they can trust their leadership to engage in their professional development, they respond with increased job satisfaction. Empowering employees in this manner reflects not just in their personal work by way of improved productivity but also in their sense of ownership of not just their own success but also success of the organization as a whole. This is the crux of the concept of employee development and inclusive growth.

Finding ways to foster inclusive growth is no longer an option but is a necessity which can significantly impact on the value of an institution It is imperative that organizational leadership anticipate the pressing issues such as: how to build the skills of tomorrow's workforce? How to support risk-taking and entrepreneurship while safeguarding job security, quality, and social protection within the microcosm of a team? In this scenario, it would be a shrewd policy for the organizational leadership to invest in a comprehensive long term Inclusive Growth Strategy (IGS) [3] that identifies the core areas of employee development considered as essential by the employees themselves and create opportunities to ensure that everyone have the skills to participate in the opportunities made available and thereby share in the benefits of growth of an organization.

\section{References}

1. Samans R, Blanke J, Corrigan G, Drzeniek M (2015) Benchmarking Inclusive growth and development, Discussion Paper. World Economic Forum.

2. The rise and responsibility of talent development in the new labor market. Workplace Learning \& Development Report 2018 Linked in Learning.

3. Kaplan S, Serafeim G, Tugendhat E (2019) Intelligent design of Inclusive Growth Strategies. Harvard Business school Working Paper. 